\title{
Frequency distribution studies of epipelic diatoms along an intertidal shore
}

\author{
Deborah R. Oppenheim \\ University of Bristol, Department of Botany; \\ Woodland Road, Bristol, BS8 1UG, U. K* *
}

\begin{abstract}
Live and dead cell counts of epipelic diatoms were analysed at 16 sites along a transect crossing a saltmarsh, sandflat, and mudflat at Berrow Flats, Somerset, U.K. Replicate monthly samples were taken from January 1982 to June 1984. The ratio of dead to live cells varied according to position along the transect. Temporal changes of the ratios did not display a cyclic seasonal pattern. The clustered mosaic of live cells and empty frustules on surface sediments was quantitatively assessed. Graphing variance against seasonal mean cell counts showed that the variance was proportional to the square of the mean. The Neyman TYpe A equation is suggested as a possible model to explain this relationship.
\end{abstract}

\section{INTRODUCTION}

There are many difficulties encountered in the extraction and analysis of diatoms associated with sediments. The separation of the diatoms from the sediment for slide preparation, the differentiation of contaminant species from those growing in situ, and distinguishing dead from living material, are some of the problems recognized (McIntire \& Moore, 1977).

Three different types of preparation are generally used: (1) oxidation of the diatom cell contents, and mounting the siliceous components in a resin of high refractive index (Hohn \& Hellerman, 1963; Hendey, 1964; Patrick \& Reimer, 1966); (2) examination of live cells using a coverglass (Lund, 1942) or various lens tissue techniques (Eaton \& Moss, 1966; Riaux, 1983); (3) achieving separation of live cells by centrifugation using LUDOX (de Jonge, 1979) or Percol gradients (Whitelam et al., 1983).

Relying on traditional acid cleaning preparations as a sampling strategy for analysis does not permit the distinction between living and dead material. The percentage of dead cells on the sediment surface can be high, and can increase species diversity when included in the calculations of diversity indices (Wilson \& Holmes, 1981). Further difficulties in obtaining a representative sample arise due to the patchiness in distribution of the live cells growing on the surface sediments (Aleem, 1950; Eaton \& Moss, 1966) and to variability within different types of sediment (Wilson \& Holmes, 1981).

Many sampling strategies used in ecological studies rely on acid cleaning methods

\footnotetext{
- Present address: Portsmouth Polytechnic, Department of Biological Sciences; King Henry I Street, Portsmouth, PO1 2DY, Hants., U.K. 
for quantitative study without fully considering the implications of the presence of empty frustules or contaminant forms.

This study examines the ratios of live to dead cells. Live and dead cells were counted on the basis of cells with or without cell contents. The degree of patchiness is also examined. As problems with variability in the environment cannot be overcome with current methods, an understanding of the limitations imposed by the effects of patchiness, and proportions of live and dead cells will ensure a more effective analysis of ecological data. If high numbers of empty frustules are present with the growing population in situ on the sediment surface, then counting live cells for ecological study is imperative. This investigation undertakes an in-depth study of the patchy mosaics of live and dead cells, not only to test this hypothesis but also to assess how such factors change seasonally and spatially along the shore.

\section{DESCRIPTION OF SITE}

Berrow Flats is located in the south western area of the Severn Estuary along the Somerset coast where it is bordered by recent deposits of alluvium lying on carboniferous limestone (Fig. 1). Sand dunes on this part of the Severn coast are limited to a five and a
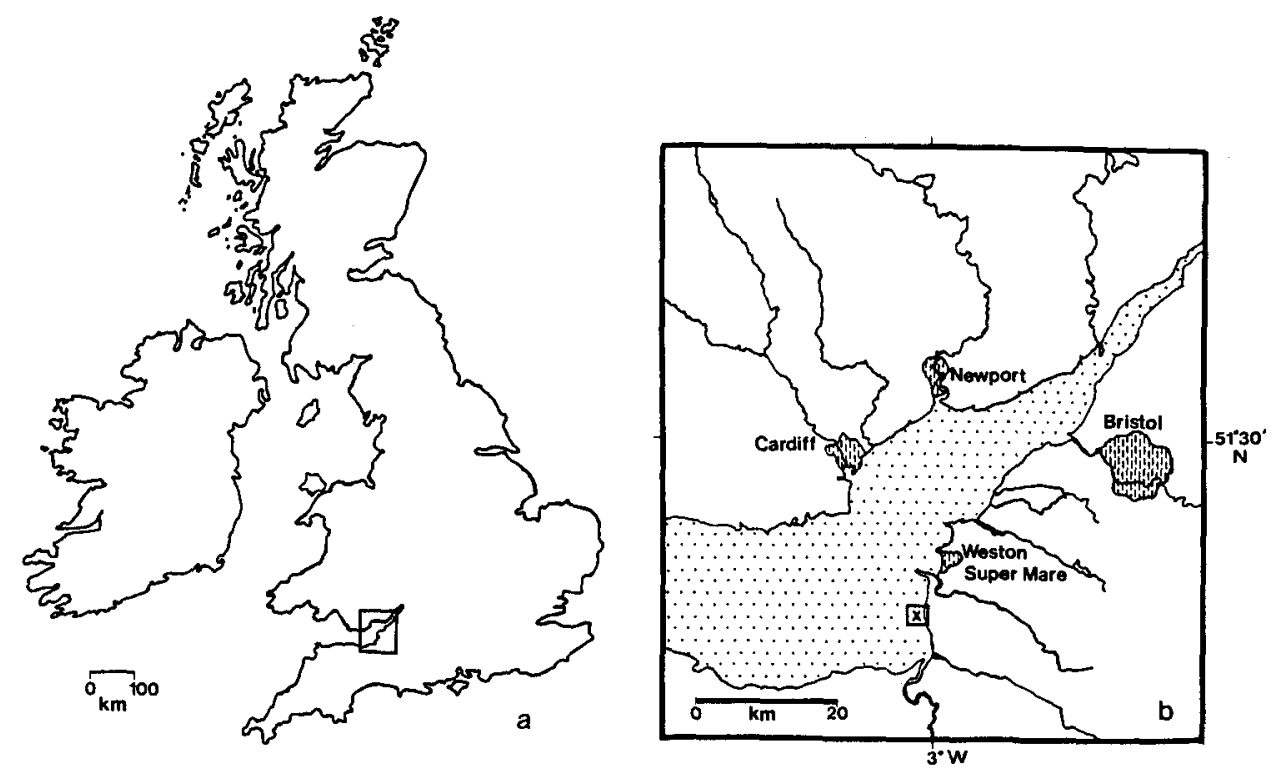

Fig. 1. Map of U.K. and the Severn Estuary (Based on map from Bassindale, 1943) showing the location of the transect site marked by an: $X$

half mile stretch facing west between Burnham-on-Sea and Brean down. The Berrow dunes are located at the southern end of this dune coast line, and here they are most extensively developed, forming parallel ridges of up to half a mile in width (HopeSimpson \& Willis, 1955).

The westerly aspect results in exposure to strong off-shore winds, and due to the tidal 
flow into the Bristol channel, more saline currents flow along the Berrow shore (Teverson, 1982). Hence a more marine influence prevails in this area of the estuary. Tidal scour is caused by wind induced wave action dissipating energy over the extensive mudflats. At low tide these mudflats extend out four and a half miles at their widest point. The extent of these mudflats offers some protection to the saltmarsh vegetation along the upper fringe of the shore. Another important water source to the study area is the freshwater drainage pipes leading from the sand dunes. The freshwater output is dependent on the mean monthly rainfall.

The study area (Fig. 2) consisted of a transect crossing a saltmarsh, sandflat, and mudflat, with 6 stations and 3 sampling sites at each station, except station VI where only

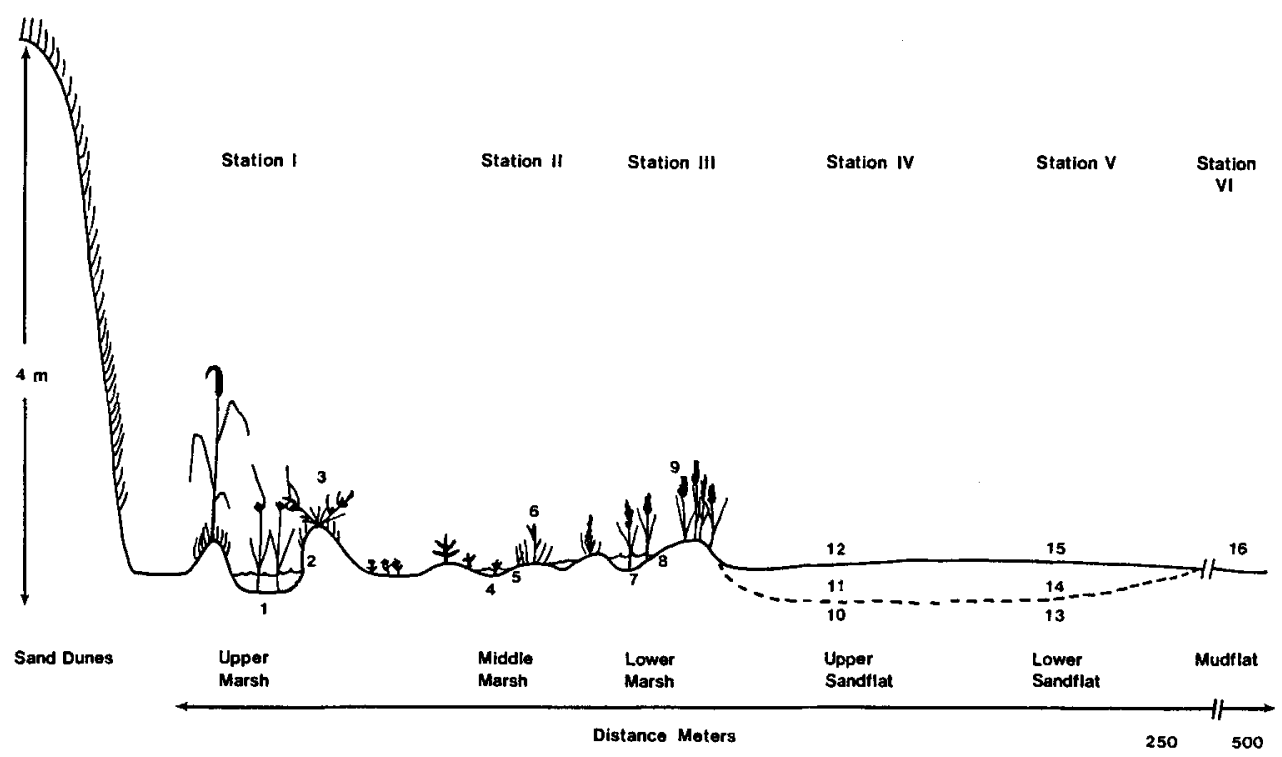

Fig. 2. Profile of the transect showing the locations of 16 sites at 6 stations across the different vegetation zones of the saltmarsh, sandflat and mudflat; ... base of stream channel in the sandflat

one site was sampled. At stations I-IV a pool, slope, and mound site were sampled. Station I was located in the upper marsh surrounded by Scirpus maritimus, Carex extensa, Typha latifolia and Phragmites communis. Station II was in the middle marsh with Salicornia spp. and Glaux maritima as the dominant higher plants. Station III, the lower marsh, was nearly completely overgrown by Spartina anglica forming a closed sward at the seaward edge of the marsh. Stations IV, V and VI were located on the upper sandflat, lower sandflat and mudflat, respectively. These areas were devoid of any vascular plant vegetation. A shallow channel cut through the sandflat, and a site at the base of the channel, the bank, and the top of the channel were sampled at stations IV and V. Monthly samples were collected at each site from January 1982 to June 1984. 


\section{MATERIALS AND METHODS}

\section{Sampling strategy}

All sites along the transect were sampled at low tide. A $250 \mathrm{~cm}^{2}$ surface area of sediment was scraped off the surface at an approximate depth of $5 \mathrm{~mm}$, and was transported back to the laboratory. The sediment was left to settle in petri dishes overnight, and a coverglass technique was then used to sample the diatoms. Each cover glass was placed on the sediment for a minimum of two hours, mounted in dilute glycerol jelly and then sealed with DEPEX (a plastic sealant). A standard surface area of $2.87 \mathrm{~mm}^{2}$ was counted on each coverglass at $400 \times$ magnification on an Olympus $C 01$ compound microscope. Large numbers of empty frustules were present on the sediment surface together with the live cells. The empty frustules also adhered to the undersurface of the coverglass due to surface tension. Therefore, both the live cells and dead cells that adhered to the undersurface of the coverglass were recorded. As dead cells could adhere as whole frustules or as individual valves, counts of valves were recorded. The results are presented in terms of numbers of valves counted from dead cells - valves or frustules without cell contents, or valves of live cells - valves of frustules containing cell structure. Duplicate counts were made at each site. The harvesting efficiency of the coverglass technique has been shown to remove only $75 \%$ of the microalgae from the sediment surface (Eaton \& Moss, 1966). However, results from the coverglass method were almost identical to direct sediment counts in terms of species composition (Eaton \& Moss, 1966). For the purpose of an initial ecological study, the method described was adequate. The work presented here demonstrates the variability in distribution of diatoms on the sediment surface which can then be applied to the analysis of ecological data.

\section{Analysis of cell counts along the shore}

Cell counts from all sites along the transect were taken during the first two years of sampling. Ratios of empty frustules to live cells were calculated for each site. Each seasonal mean was taken from six separate counts taken over a three-month period. The percentage of empty frustules was also calculated in the same fashion.

\section{Analysis of seasonal changes in cell counts}

Two approaches were undertaken. Initially, 10 coverglasses were removed from the sediment by the method described above from one mud sample. The mean and variance of the dominant taxa were then calculated from 10 replicates.

To establish a relationship between the variance and the mean from the monthly diatom counts, seasonal means of total diatom counts and their corresponding variance were calculated from two years data. Therefore, each mean represents duplicate counts for three months samples at a given site from a total of 768 samples from all sites. Graphing each mean to its corresponding variance produced a curve. In order to compare the slope of these curves to the straight line of a Poisson distribution, a log-log plot of the results was produced. 


\section{RESULTS}

Spatial changes in the ratios of live and dead cells along the shore

The results from 1982 and 1983 (Figs 3 and 4) show that higher ratios of dead cells occurred at the sandflat sites on the intertidal shore. The sandflat ratios were higher in spring and summer in 1982, with the highest ratio of 55 at site 15 in the summer of 1982. A less marked difference was observed along the transect in autumn and winter. The winter ratios in 1982 were slightly higher in the saltmarsh than in the sandflat. However, this seasonal pattern was not repeated in 1983 (Fig. 4). All ratios at sandflat sites were higher than at the saltmarsh at all times in the year. Most of the ratios were smaller than in the previous year. As the transect progressed out towards the sea, higher ratios were gradually recorded. Percentages of dead cells recorded are summarized in Table 1. All counts from all months from 1982-1983 had significantly high percentages of dead cells (>5\%). In May 1983, $71 \%$ of all valves counted were derived from dead cells. Mean monthly percentages were never lower than $13 \%$ (March 1983). Percentages of individual counts (used to calculate the means in Table 1) were as high as $86 \%$.

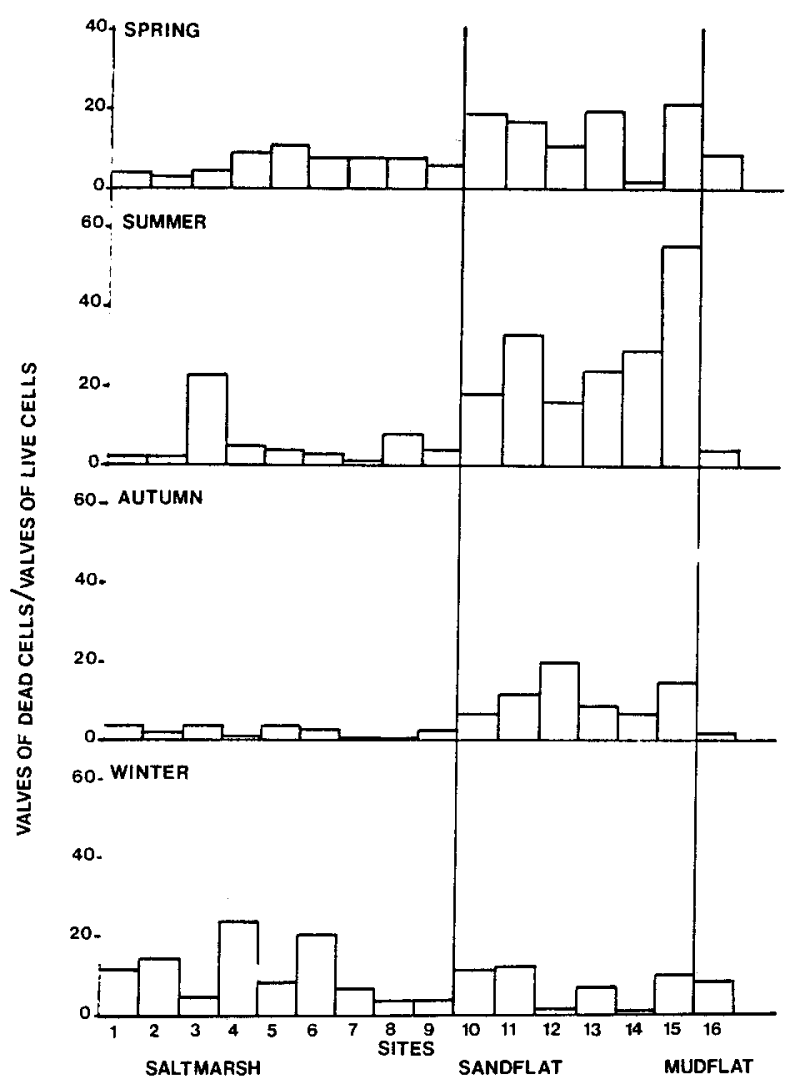

Fig. 3. Seasonal ratios of empty frustules to live cells along the transect in 1982 
Table 1. Mean percentages of valves from empty frustules calculated from all counts at all sites for each month showing significantly high proportions of the dead population $(>5 \%)$

\begin{tabular}{|lll|}
\hline Month & 1982 & Percentage \\
& & 1983 \\
\hline & 31 & \\
January & 58 & 44 \\
February & 37 & 35 \\
March & 35 & 13 \\
April & 23 & 58 \\
May & 56 & 51 \\
June & 44 & 41 \\
July & 42 & 46 \\
August & 25 & 62 \\
September & 23 & 47 \\
October & 40 & 53 \\
November & 27 & 38 \\
December & & \\
\hline
\end{tabular}

Seasonal changes in variability of the cell counts

The mean and variance calculated for the counts of the dominant taxa taken from 10 replicates quantitatively defines the patchy distribution on the sediment. The results (Table 2) clearly show that the size of the variance exceeds the size of the mean by as much as 2 orders of magnitude. If the distribution had been random, viz. a Poisson distribution, the variance would equal the size of the mean. Results from field data (Fig. 5) shows that in all cases both live cell counts and dead cell counts in 1982 and 1983

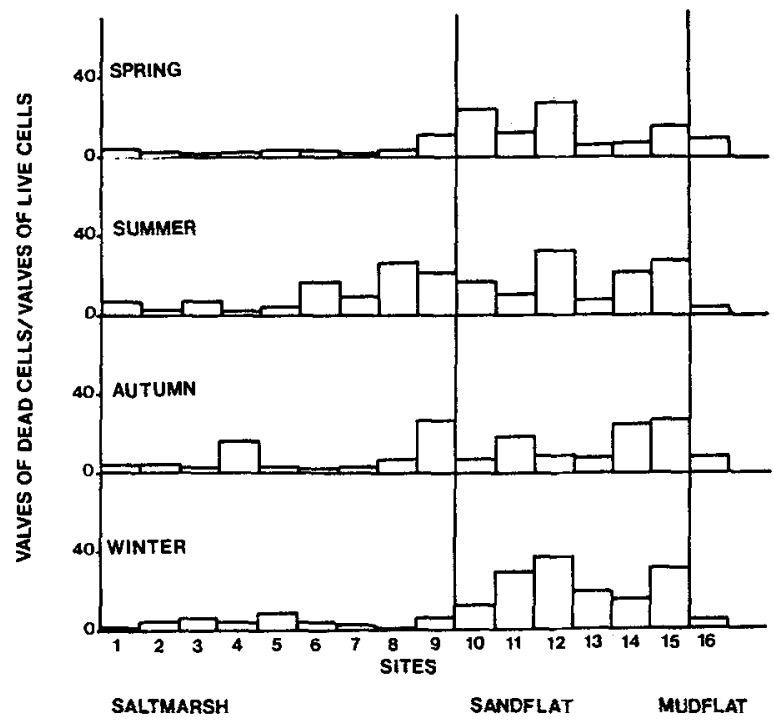

Fig. 4. Seasonal ratios of empty frustules to live cells along the transect in 1983 
Table 2. The mean and variance of 10 replicate counts of 2 diatom taxa and 1 cyanobacterium with the highest counts at two sites. The results show the variance exceeds the size of the mean

\begin{tabular}{|lcc|}
\hline \multicolumn{1}{|c|}{ Species } & Mean & Variance \\
\hline Site 13 & & \\
Nitzschia vacillata & 47.1 & 2018 \\
Nitzschia closterium & 19.1 & 770 \\
Site 4 & & \\
Nitzschia closterium & 14.2 & 124 \\
Anabaena cylindrica & 239.6 & 67436 \\
\hline
\end{tabular}
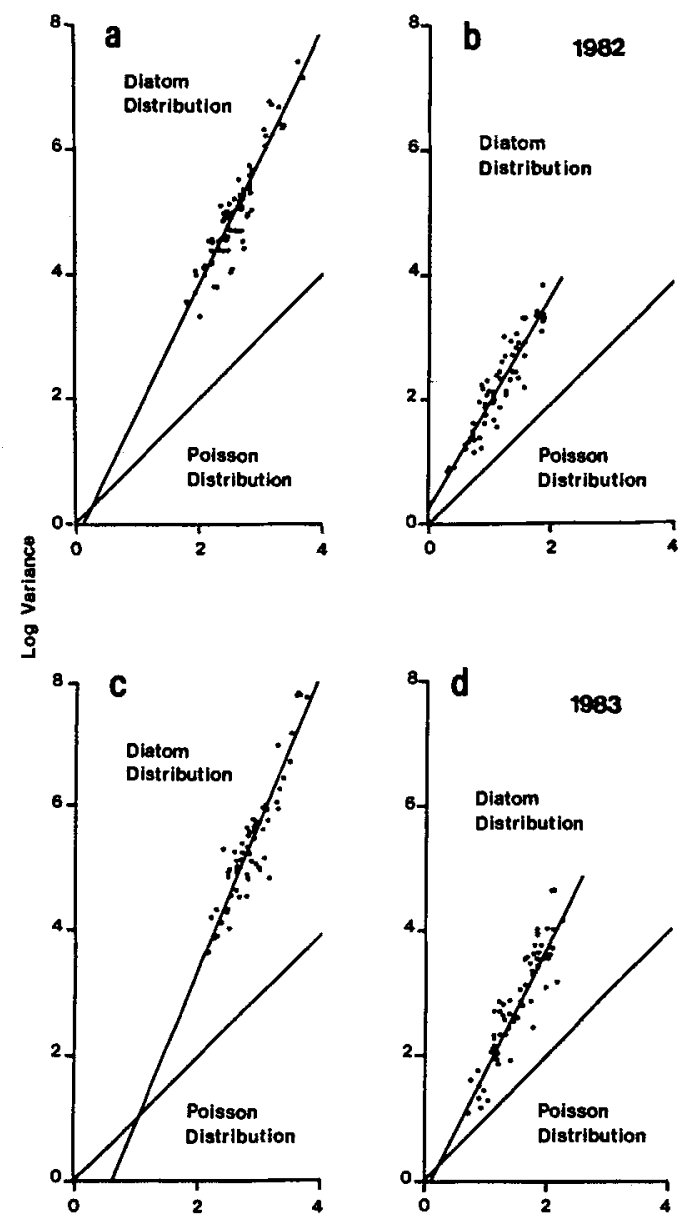

Fig. 5. Diatom distribution expressed as log counts observed in $1982(a, b)$ and $1983(c, d)$ compared with a Poisson distribution. $a$ and $c$ : counts of valves of live cells; $b$ and $d$ : counts of valves of dead cells 


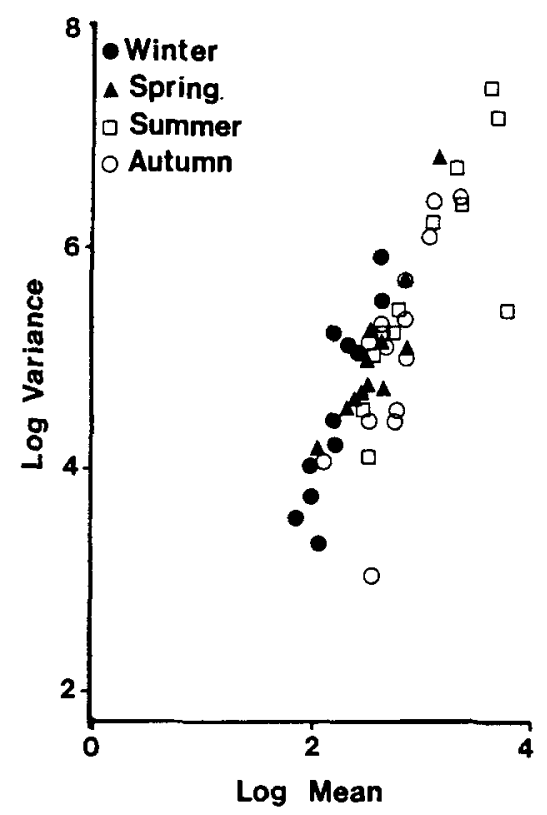

Fig. 6. Scatter plot of the seasonal distribution of live cells recorded in 1982

were straight line graphs of slope approximately 2 . Therefore the variance is proportional to the square of the mean. Further examination of the scatter plots (Fig. 6) reveals that the points are positioned along the regression line according to season, with winter means at the bottom, spring and autumn means in the middle, and summer means at the top.

\section{DISCUSSION}

This study of the ratios of live and dead cells from Berrow Flats, confirms that significantly high numbers of empty frustules occur on the surface sediments together with the live cells at all sites along the transect at all months of the year. Higher numbers of empty frustules occurred at sandflat and mudflat sites than at the saltmarsh. This may be due to increased tidal scour because these sites are lower down the shore and subject to daily tidal submergence by spring and neap tides. When the ratio of dead to living cells recovered from sediments can be as high as $1: 2$, then the importance of counting live cells cannot be ignored. Therefore counting live cells for ecological study is essential. These conclusions agree with those of Wilson \& Holmes (1981).

The degree of patchiness of the living population (as well as the dead cells) has not only been confirmed to be non-random, but the variability of a mean count changes with population density at a constant rate. Although the accuracy of a given count changes with population density, variability can be predicted, and its limitation on the final analysis clarified. If a short-term pilot study had been undertaken, e.g. in winter when the mean and variance were low and appeared proportional, the information would be misleading. Therefore a long-term examination of any field sampling strategy is recommended. 
The empty frustules also display a clustered distribution indicating that tidal scour does not disperse dead cells evenly over the sediment surface. One possible explanation is that mucilage secreted from living cells may maintain clusters of empty frustules in coherent units. Further study of this phenomenon is required, examining the fate of species following periods of peak growth.

Plotting the log variance against the log mean is simply a means of demonstrating a clear relationship between these two variables. The results do not account for all the sources of variability (of which there are many), but defines the variation in a way that allows the worker to predict variability with respect to mean cell number. Future sampling strategies must attempt to randomize this small-scale variation.by developing a harvesting technique which can disperse the surface clusters.

Individuals behaving as dependent units (i.e. forming aggregates) is not an unusual phenomenon. Many examples of clustering, whereby the variance is proportional to the square of the mean or greater, has been observed (Taylor, 1961). Various theoretical expressions used to describe field distributions have been suggested (reviewed in Venrick, 1978). The model that best describes the clustering observed in these results is the Neyman Type A equation (Pielou, 1969), defining a continuous spatial pattern:

$$
\operatorname{Pr}=\mathrm{e}^{-\lambda_{1}} \frac{\lambda_{2}}{\mathrm{r} !} \sum_{\mathrm{j}=0}^{\infty} \frac{\left(\lambda_{1} \mathrm{e}^{-\lambda_{2}}\right)^{\mathrm{j}}}{\mathrm{j} !} \cdot \mathrm{jr}
$$

This model considers patchiness to be described by two main variables: the mean number of individuals within a cluster $\left(\lambda_{2}\right)$ and the mean number of clusters per unit area $\left(\lambda_{1}\right)$. Knowing the number of individuals $(r)$, the probability of a unit containing $r$ individuals ( $\mathrm{Pr}$ ) can be calculated. Pielou (1969) considers these two variables $\left(\lambda_{1}, \lambda_{2}\right)$ to have a specified pattern that is superimposed so that both entities will give rise to a Poisson distribution. Taking this assumption into account an expression of the mean can be calculated (Pielou, 1969):

$$
\overline{\mathrm{X}}=\lambda_{1} \lambda_{2}
$$

and an expression for the variance (Pielou, 1969):

$$
\text { Variance }=\lambda_{1} \lambda_{2}\left(1+\lambda_{2}\right)
$$

The variance will give values which obviously exceed the mean, and could express a relationship where the variance increases at a rate square to the mean.

Summarizing the model above, in terms of the diatom distribution, the following events could take place: a diatom moves onto the sediment surface and divides. Once division has taken place and the diatoms stick together and do not move as independent units, they display a non-random distribution. As diatom division continues, and clusters form, two sources of variability arise: the mean number of diatom clusters per coverglass, and the mean number of diatoms within each cluster. The larger the cluster size, the greater the variability encountered.

All counts from the fieldwork of this project were of the total number of individuals per unit area; therefore the data cannot be applied to the equations just described. It is also recognized that the data gathered for this analysis represents the patchy distribution of diatoms settled within a petri dish. However, clustering has been observed in the natural environment. Initial counts taken from coverglasses left in the field have yielded 
the same results, but further work is required. Many other factors may influence the spatial patterns observed such as varying birth and death rates, or varying environmental factors.

Nevertheless, it is likely that more than one source of variability is responsible for the clustered array of live and dead cells over the sediment surface. The Neyman Type A equation provides a good starting point from which an understanding of clustering by the diatoms can be achieved. Such a non-random distribution must be understood if correct statistical analysis is employed, and the data of a long-term ecological study analysed.

Acknowledgements. I am indebted to Professor F. E. Round for his supervision of this study. I am also grateful to Drs. M. Jarman and M. J. Burfitt for their advice on statistics, and I thank Dr. R. L. Fletcher for helpful comments on the manuscript. This project was supported by an ORS award granted by the CVCP of the United Kingdom.

\section{LITERATURE CITED}

Aleem, A. A., 1950. The diatom community inhabiting the mudflats at Whitestable. - New Phytol. 49, 174-188.

Bassindale, R., 1943. Studies on the biology of the Bristol Channel. 1. The physical environment and intertidal fauna of the southern shores of the Bristol Channel and Severn Estuary. - J. Ecol. 31-32, 1-29.

Eaton, J. W. \& Moss B., 1966. The estimation of numbers and pigment contents in epipelic algal populations. - Limnol. Oceanogr. 11, 584-595.

Hendey, N. I., 1964. An introductory account of the smaller algae of British coastal waters. - Fishery Invest., Lond. (Ser. 4) 5, 1-317.

Hohn, M. H. \& Hellerman, J., 1963. The taxonomy and structure of diatom populations from three eastern North American rivers using three sampling methods. - Trans. Am. microsc. Soc., 82, 250-329.

Hope-Simpson, J. F. \& Willis, A. J., 1955. Vegetation. In: Bristol and its adjoining counties. Ed. by C. M. MacInnes \& N. F. Whittard. B.A.A.S., London, 91-93.

Jonge, V. N. de, 1979. Quantitative separation of benthic diatoms from sediments using density gradient centrifugation in the colloidal silica LUDOX-TM. - Mar. Biol. 51, 267-278.

Lund, J. W. G., 1942. Marginal algae of certain ponds with special reference to bottom deposits. - J. Ecol. 30, 245-283.

McIntire, C. D. \& Moore, W. M., 1977. Marine littoral diatoms - ecological considerations. In: The biology of diatoms. Ed. by D. Werner. Blackwell, Oxford, 333-371.

Patrick, R. \& Reimer, C. W., 1966. The diatoms of the United States. - Monogr. Philadelphia Acad. nat. Sci., 13, 1-688.

Pielou, E. C., 1969. An introduction to mathematical ecology. Wiley-Interscience, New York, 1-286.

Riaux, C., 1983. Structure d'un peuplement estuarien de diatomées épipéliques du Nord-Finistère. Oceanologica Acta 6, 173-183.

Taylor, L. R., 1961. Aggregation, variance and the mean. - Nature, Lond. 100, 732-735.

Teverson, R., 1982. Saltmarsh ecology in the Severn Estuary. - Internal Rep. Dept. Zool., Bristol Univ., Dept. Energy Contract Agreement. Ref. Nr. UKAEA E/SA/CON/1619/51/054, 1-100.

Venrick, E. L., 1978. Sampling design, sampling strategies. In: Phytoplankton manual. Ed. by A. Sournis. Unesco, Paris, 1-7.

Whitelam, G. C., Lanarasi, T. \& Coop, G. A., 1983. Rapid separation of microalgae by density gradient centrifugation in percol. - Br. phycol. J. 18, 23-28.

Wilson, C. J. \& Holmes, R. W., 1981. The ecological importance of distinguishing between living and dead diatoms in estuarine sediments. - Br. phycol. J. 16, 345-349. 